\title{
DEBATE
}

\section{Present self-represented futures of value are a reason for the wrongness of killing}

\section{S J Parsons}

In Marquis's recent paper he has not satisfactorily shown that killing does not adversely affect the victim's present self-represented desires for their future. Marquis is correct in believing life and death are distinct, but living and dying are not. In fact, to use a well-known saying, "the second we are born we start to die". During the process of dying, whether it be long as in over our lifetime or short as in as we are being killed, there comes a point when the present realistic desires we have we know will never be satisfied. This is why killing can be wrong. This would imply killing an unconscious person, infant, or fetus cannot be wrong. But such killing can be wrong, despite the person killed not experiencing the desire not to be killed as he was dying. Killing can be wrong because others can have a present selfrepresented desire for that person not to be killed to have been killed. If this line of reasoning is correct, then the "best interests" principle often applied to life and death considerations regarding unconscious persons, infants, and fetuses, is invalid, as such human beings do not have present desires. All that matters is what relevant others rationally desire, after being informed of the facts and the consequences, for that unconscious person, infant or fetus.

M arquis believes killing is wrong because it deprives us of our potential future of value. ${ }^{1}$ Brown believes it is our self-represented future of value, requiring consciousness, that better explains the wrongness of killing and does not imply abortion is wrong. ${ }^{2}$

In his recent analysis of Brown's paper, Marquis states that both his potential future of value account and Brown's self-represented future of value account give "comparable" reasons for the wrongness of killing. In fact, he states that the self-represented version, "if there was nothing more to be said", would be the preferred account for reasons of gender equality, thus allowing abortion. ${ }^{3}$ Of course, there is more to be said. He divides the self-represented account into present, future present and future versions, and rejects all three. This paper will discuss his criticisms of the two present versions, hopefully showing that Marquis cannot reject a present version and must then accept the permissibility of abortion.

In the present version, Marquis says "what killing wrongfully deprives one of is a present mental state, not a future state". To reject this version, Marquis makes use of the famous Epicurean epigram "when I am, death is not and when death is, I am not". He claims that "what I now have, I have, whatever you do ... . [the only thing] you can now deprive me of [by killing me] is a mental representation I would have had in the immediate . . future". There is no doubt that killing deprives one of a future. But is this wrong? There are two options when answering this. First, if one believes in the afterlife, death in fact should be more desirable than life. If you believe once you are dead you cease to exist, death cannot be undesirable as it is simply non-existence. After all, it is dying that most of us are afraid of, not death itself. There is no ongoing realisation of a loss once we are dead, except by others, and this is why we often are most sorrowful after the death of a person for those left behind. These "others" are important, a point that will be brought up again.

What does matter is what we think when we are alive, which includes when we are dying. Marquis is correct in believing life and death are distinct, but living and dying are not. In fact, to use another well-known saying, "the second we are born we start to die". During the process of dying, whether it be long as in over our lifetime or short as in as we are being killed, there comes a point when the present realistic desires we have we know will never be satisfied. This is why killing can be wrong. Although Marquis is correct in saying "what I have now, I have, whatever you do", what you do to me in the process of killing me is alter what I have now into something I do not desire-the loss of my future. Thus, the present selfrepresented future of value account of the wrongness of killing stands correct, but not because a conscious desire for the future is thwarted by killing, but because the present state of mind one is in becomes undesirable during the process of dying in this manner. This explains why it is possible to "die in peace". It is possible to have a desirable state of mind when dying, for instance at the inevitable end of a happy and long life, or the end of a shorter but unbearably painful one.

The present version account just elucidated implies that if someone is killed instantaneously and unexpectedly, without time for the person who has just died to realise the loss of a future they desired, it cannot be wrong. An instantaneous death gives, literally, no time for a disturbance of one's desires for the future. Similarly, for a killing occurring during sleep or unconsciousness, there is no present desire to disturb. Such deaths are intuitively less unfortunate for this reason. But they can still be wrong.

How can the instantaneous, unexpected killing of a person who did not desire their death be wrong? It can be wrong simply because those of us left behind, have a present self-represented desire for such an act not to happen or to have happened to that person, nor to ourselves or another. Killing can be wrong because the person killed experienced the desire not to be killed as he was dying, but also because others can have a present self-represented desire for that person not to be killed or to have been killed. It is simply that others may not want the killing to happen or have happened. And this is usually the case if that person is only temporarily unconscious, say in the case of a man after a head injury with a good prognosis. His wife knows that he will awaken and again desire his life, and she presently desires this to occur. Thus, he is cared for to achieve that end.

If this line of reasoning is correct, then the "best interests" principle often applied to life and death considerations regarding unconscious persons, infants, and fetuses, is invalid, 
as such human beings do not have present desires. All that matters is what relevant others rationally desire, after being informed of the facts and consequences, for that unconscious person, infant or fetus. The important issue of what constitutes a rational and hence valid desire, and how we should protect fetuses, infants and unconscious persons from the irrational desires of others is the topic of another paper.

Now returning to another of Marquis' arguments, he also believes a future present version of Brown's self-represented future of value is false, despite it "not underwrit[ing] the permissibility of abortion". Marquis claims many future present desires for a future can be thwarted by knowledge alone, such as news of terminal cancer. Thus, telling a patient they have cancer can be as wrong as killing them. This is nonsense. The reason is that bad news may alter some, but rarely all, of a person's present desires for a future of value. Bad news simply allows a person to presently hold, both now and in the future, only realistic desires for their future. Should accurate and truthful bad news remove all of a person's present desires for anything, then they will want to die, and rightly so. Killing someone forces the realisation of the whole loss of one's future, and is a way of "delivering bad news" that can clearly be wrong.

Marquis has not satisfactorily shown that killing does not adversely affect the victim's present self-represented desires for their future. Thus, must he now prefer this over his own potential future of value account of the wrongness of killing and allow abortion?

\section{REFERENCES}

1 Marquis D. Why abortion is immoral. Journal of Philosophy 1989;86: 183-202

2 Brown $M$. The morality of abortion and the deprivation of futures. Journal of Medical Ethics 2000;26:103-7

3 Marquis D. Deprivations, futures and the wrongness of killing. Journal of Medical Ethics 2001;27:363-9. 